\title{
Glutathione S-transferase Mu 2-transduced mesenchymal stem cells ameliorated anti-glomerular basement membrane antibody-induced glomerulonephritis by inhibiting oxidation and inflammation
}

Yajuan Li ${ }^{1,2}$, Mei Yan', Jichen Yang ${ }^{3}$, Indu Raman ${ }^{1}$, Yong Du', Soyoun Min ${ }^{1}$, Xiangdong Fang ${ }^{2}$, Chandra Mohan ${ }^{1,4}$ and Quan-Zhen Li ${ }^{1,5^{*}}$

\begin{abstract}
Introduction: Oxidative stress is implicated in tissue inflammation, and plays an important role in the pathogenesis of immune-mediated nephritis. Using the anti-glomerular basement membrane antibody-induced glomerulonephritis (anti-GBM-GN) mouse model, we found that increased expression of glutathione S-transferase Mu 2 (GSTM2) was related to reduced renal damage caused by anti-GBM antibodies. Furthermore, mesenchymal stem cell (MSC)based therapy has shed light on the treatment of immune-mediated kidney diseases. The aim of this study was to investigate if MSCs could be utilized as vehicles to deliver the GSTM2 gene product into the kidney and to evaluate its potential therapeutic effect on anti-GBM-GN.
\end{abstract}

Methods: The human GSTM2 gene (hGSTM2) was transduced into mouse bone marrow-derived MSCs via a lentivirus vector to create a stable cell line (hGSTM2-MSC). The cultured hGSTM2-MSCs were treated with $0.5 \mathrm{mM}$ $\mathrm{H}_{2} \mathrm{O}_{2}$, and apoptotic cells were measured by terminal dUTP nick-end labeling (TUNEL) assay. The 129/svj mice, which were challenged with anti-GBM antibodies, were injected with $10^{6}$ hGSTM2-MSCs via the tail vein. Expression of hGSTM2 and inflammatory cytokines in the kidney was assayed by quantitative PCR and western blotting. Renal function of mice was evaluated by monitoring proteinuria and levels of blood urea nitrogen (BUN), and renal pathological changes were analyzed by histochemistry. Immunohistochemical analysis was performed to measure inflammatory cell infiltration and renal cell apoptosis.

(Continued on next page)

\footnotetext{
* Correspondence: quan.li@utsouthwestern.edu

${ }^{1}$ Department of Immunology and Internal Medicine, University of Texas

Southwestern Medical Center, 5323 Harry Hines Blvd, Dallas, TX 75390-8814,

USA

${ }^{5}$ Key Laboratory of Medical Genetics, Wenzhou Medical University School of

Laboratory Medicine and Life Science, Wenzhou 325035, China

Full list of author information is available at the end of the article
} 
(Continued from previous page)

Results: MSCs transduced with hGSTM2 exhibited similar growth and differentiation properties to MSCS. hGSTM2-MSCs persistently expressed hGSTM2 and resisted $\mathrm{H}_{2} \mathrm{O}_{2}$-induced apoptosis. Upon injection into 129/svj mice, hGSTM2-MSCs migrated to the kidney and expressed hGSTM2. The anti-GBM-GN mice treated with hGSTM2-MSCs exhibited reduced proteinuria and BUN (58\% and 59\% reduction, respectively) and ameliorated renal pathological damage, compared with control mice. Mice injected with hGSTM2-MSCs showed alleviated renal inflammatory cell infiltration and reduced expression of chemokine (C-C motif) ligand 2 (CCL2), interleukin (IL)-1 $\beta$ and IL-6 (53\%, 46\% and 52\% reduction, respectively), compared with controls. Moreover, hGSTM2-MSCs increased expression of renal superoxide dismutase and catalase, which may associate with detoxifying reactive oxygen species to prevent oxidative renal damage.

Conclusions: Our data suggest that the enhanced protective effect of GSTM2-transduced MSCs against anti-GBM-GN might be associated with inhibition of oxidative stress-induced renal cell apoptosis and inflammation, through over-expression of hGSTM2 in mouse kidneys.

\section{Introduction}

Anti-glomerular basement membrane antibody-induced glomerulonephritis (anti-GBM-GN) is an autoimmune disorder in which circulating antibodies against the $\alpha-3$ chain of type IV collagen bind to renal GBM and initiate an inflammatory reaction [1,2]. Anti-GBM-GN is one of the most severe forms of glomerulonephritis, characterized by crescent formation and linear glomerular deposits of IgG [3]. Patients usually present with rapidly progressive glomerulonephritis, hematuria and subnephrotic range proteinuria. About $40-70 \%$ of patients develop end-stage renal disease [4].

It has been reported that oxidative stress plays an important role in the pathogenesis of anti-GBM-GN, and is one of the major causes of tubulointerstitial injury [5-7]. During oxidative stress, cellular metabolism produces excessive reactive oxygen species (ROS), which modulate various physiological functions and affect innate immunity in infectious and non-infectious inflammation. ROS serve as the main products of innate immunity during the course of inflammation [8]. Overproduction of ROS, reactive nitrogen species, and reactive chlorine species by inflammatory cells in nephritis can cause further tissue damage, intensify inflammation, promote apoptosis, and accelerate the progression of nephritis $[9,10]$. Under physiologic conditions, there are several anti-oxidant defense mechanisms available to limit the oxidative damage. Superoxide dismutase (SOD) and catalase (CAT) are the two main anti-oxidant enzymes. SOD catalyzes the dismutation of superoxide into oxygen and hydrogen peroxide $\left(\mathrm{H}_{2} \mathrm{O}_{2}\right)$, with the latter subsequently degraded to water and molecular oxygen by CAT or glutathione peroxidase (GPX) in the presence of reduced glutathione.

Anti-GBM-GN has been used as a model for the study of lupus nephritis because the two conditions share some common molecular pathways [11]. Our previous study showed that anti-GBM antibody challenge induced severe GN in some mouse strains such as 129/svj, DBA1, and NZW, whereas some other strains, such as B6 and BALB/c, were resistant to anti-GBM challenge, exhibiting no or very mild GN [12]. Comparing the gene expression profiles in the mouse kidneys revealed that a cluster of redox-related genes was differentially expressed between anti-GBM-resistant and anti-GBMsensitive strains. Glutathione S-transferase $\mathrm{Mu} 2$, a protein involved in detoxification of ROS, was significantly increased in anti-GBM-resistant strains (B6 and BALB/c), but decreased in anti-GBM-sensitive strains (129/svj, DBA1, and NZW), suggesting that GSTM2 may play a protective role in anti-GBM induced nephritis.

GSTM2 is a member of the glutathione S-transferase (GST) family, which participates in detoxification of ROS [13]. GSTs act as biotransformation enzymes, and exist widely in various mammalian tissues, including kidney. They play a major role in cellular anti-oxidant defense mechanisms by catalyzing the reduction of potentially harmful peroxides [14-16]. In order to elucidate the potential protective role of GSTM2 in the pathogenesis of immune-mediated nephritis, and also to explore possible therapeutic approaches using this molecule for lupus nephritis, we used genetically modified mesenchymal stem cells (MSCs) as carriers to deliver GSTM2 into the kidney of anti-GBM antibody-challenged mice, and evaluated the effects of these MSCs on anti-GBM-GN.

\section{Materials and methods}

\section{Microarray and gene expression analysis}

Microarray analysis on anti-GBM challenged mice has been described previously [17], and the renal gene expression profiles from five mouse strains (B6, BALB/c, $129 /$ svj, DBA1, and NZW) were deposited in the GEO database (accession number GSE53611). The expression value of redox-related genes was extracted from the microarray data and compared for the different strains. TaqMan real-time quantitative PCR (RT-qPCR) assay 
was used to further confirm the expression data obtained from microarray.

\section{Cloning of the GSTM2 gene into a lentiviral vector} Total RNA was extracted from human K562 cells with an RNeasy kit (Qiagen, Valencia, CA, USA) and reversetranscribed to generate cDNA with Superscript III using random primer (Invitrogen, Carlsbad, CA, USA). Human GSTM2 coding domain sequence (nucleotides 95 to 751, contains 219 amino acids) was amplified by PCR using the primers shown in Table 1. The hGSTM2 fragment was cloned into multiple cloning sites (MCSs) of a lentiviral vector pCDH-MSCV-MCS-EF1-GFP-Puro (System Biosciences, Mountain View, CA, USA) using $\mathrm{XbaI}$ and BamHI restriction enzyme cutting sites. The resulting recombinant (pCDH-hGSTM2) DNA was amplified in vitro, and the sequence was verified by sequencing analysis.

\section{Transducing $\mathrm{pCDH}$-hGSTM2 into MSCs}

MSCs were isolated from B6 bone marrow and cultured in DMEM (Sigma-Aldrich, St. Louis, MO, USA). The cultured MSCs were grown to passage 5, and transduced with pCDH-hGSTM2 to generate an hGSTM2-MSC cell line using lentivector expression systems (System Biosciences). Briefly, pCDH-hGSTM2 was transfected into 293TN packaging cells with packaging plasmids, and the virus particles were collected after 48 hours of cell transfection. The MSCs were infected with purified pCDHhGSTM2 virus, and cultured for 72 hours with addition of $8 \mu \mathrm{g} / \mathrm{ml}$ polybrene (Sigma-AldrichO), then the transduced cells were selected with $3 \mu \mathrm{g} / \mathrm{ml}$ puromycin. The percentages of GFP-positive cells in MSCs transduced with $\mathrm{pCDH}$ (vector) or pCDH-hGSTM2 were about $50 \%$ and $25 \%$, respectively. Cell sorting by flow cytometry was used to enrich for the GFP-positive cells in both pCDH-MSCs and hGSTM2-MSCs. Expression of recombinant hGSTM2 in MSCs was assayed by RT-qPCR and western blotting. MSCs transduced with $\mathrm{pCDH}$ vector (pCDH-MSCs) were used as control. Only lower passage cells (before passage 10) were used for experiments.

\section{MSC proliferation and differentiation assay Proliferation}

hGSTM2-MSCs were seeded in six-well plates at $10^{4}$ cells/well and cultured in DMEM at $37^{\circ} \mathrm{C}$ with $5 \% \mathrm{CO}_{2}$ for 7 days. A set of plates was removed every 24 hours, and the cells were detached with $0.25 \%$ Trypsin-EDTA,

Table 1 Primers used for PCR analysis

\begin{tabular}{ll}
\hline Direction & Sequence $\mathbf{5}^{\prime} \rightarrow \mathbf{3}^{\prime}$ \\
\hline Forward & GCTGCAGAATCCACAGCAAC \\
Reverse & CGCAAGGCCCTACTTGTTGC \\
\hline
\end{tabular}

then the total number of cells was counted under a microscope. Proliferation of untransduced MSCs and pCDH-MSCs (control cells) was also assayed. Triplicate wells were counted for each cell type at each time point.

\section{Differentiation}

The differentiation potential of hGSTM2-MSCs was tested by assays for adipogenesis and osteogenesis. Briefly, $2 \times 10^{4}$ cells were seeded in six-well plates. For adipogenic differentiation, the cultured cells were incubated in DMEM containing $50 \mu \mathrm{g} / \mathrm{ml}$ indomethacin, 0.1 $\mu \mathrm{M}$ dexamethasone, and $50 \mu \mathrm{g} / \mathrm{ml} \mathrm{L}$-ascorbic acid 2phosphate sesquimagnesium salt hydrate (all SigmaAldrich). For osteogenic differentiation, the cultured cells were incubated in medium supplemented with 10 $\mathrm{mM} \beta$-glycerophosphate disodium salt hydrate, $50 \mu \mathrm{g} / \mathrm{ml}$ L-ascorbic acid 2-phosphate sesquimagnesium salt hydrate, and $0.1 \mu \mathrm{M}$ dexamethasone (all Sigma-Aldrich).

The culture medium was changed every 3 days for up to 3 weeks. The adipogenic lineage cells were fixed in $10 \%$ formalin for 30 minutes and stained with Oil Red O (Sigma-Aldrich), and the osteogenic lineage cells were also fixed with $10 \%$ formalin for 30 minutes at room temperature and stained with Alizarin red $(\mathrm{pH} 4.0$; Sigma-Aldrich) for 30 minutes. The stained cells were observed under the microscope.

\section{Detection of $\mathrm{H}_{2} \mathrm{O}_{2}$-induced apoptosis in vitro}

hGSTM2-MSCs $\left(2 \times 10^{5}\right)$ were seeded in six-well plates containing poly-L-lysine-coated slides. When the cells in each well were 60 to $70 \%$ confluent, the medium in each well was removed and replaced with fresh DMEM medium with or without $0.5 \mathrm{mM} \mathrm{H}_{2} \mathrm{O}_{2}$, and the cells were cultured for a further 6 hours. Apoptotic cells were stained using an In Situ Cell Death Detection Kit (Roche, Indianapolis, IN) and the cell nuclei were stained with Vectashield mounting medium containing DAPI (Vector Laboratories Inc, Burlingame, CA, USA). Apoptotic cells were identified by their distinct condensed nuclei. Images were acquired using a DFC420 microscope and Application Suite Advanced Fluorescence software (Leica, Buffalo Grove, IL, USA). pCDH-MSCs and untransduced MSCs were used as controls.

\section{Animal experiments}

Animal experiments were performed in accordance with the guidelines of the Institutional Animal Care and Use Committee of the University of Texas Southwestern Medical Center (UTSW), and were approved by the institutional ethics committee of UTSW.

To monitor the migration and localization of MSCs in mouse kidney, three $129 /$ svj mice were injected with $10^{6}$ transduced MSCs via the tail vein, and renal sections were examined for GFP signal under fluorescence 
microscope at days 3, 5, and 7 after injection. GFP signal was also monitored in three mice injected with PBS as controls.

The protective effect of hGSTM2-MSCs was evaluated using the anti-GBM-GN mouse model as described previously [17]. Briefly, 2-month-old 129/svj mice (Jackson Laboratories, Bar Harbor, ME, USA) were randomly divided into two groups of eight mice each, and challenged with rabbit anti-mouse GBM serum [18]. Two days after anti-GBM challenge, mice were injected via the tail vein either with $10^{6}$ hGSTM2MSCs (group 1) or $10^{6} \mathrm{pCDH}-\mathrm{MSCs}$ (group 2). All mice were housed at constant room temperature with free access to water and food, and were observed for 3 weeks. Blood and urine samples were collected at days 0 (pretreatment), 14, and 21 of challenge, and assayed for proteinuria and BUN. All mice were euthanized at day 21 , and tissues were collected and frozen at $-80^{\circ} \mathrm{C}$ for further analysis. Kidneys were removed and snapfrozen in liquid nitrogen, or fixed in formaldehyde for immunohistochemical analysis.

\section{Western blotting analysis}

Expression of hGSTM2 was assayed by western blotting in cultured hGSTM2-MSCs and in the kidneys of hGSTM2-MSC-injected mice. Proteins extracted from cultured hGSTM2-MSCs or mouse kidneys were run in 4 to $10 \%$ SDS-PAGE gel, and transferred to PVDF membranes. After blocking with 5\% milk, the PVDF was incubated with primary antibodies (rabbit anti-human GSTM2 antibody, 1:800 dilution, rabbit anti-GAPDH antibody, 1:500 dilution; Santa Cruz Biotechnologies, Santa Cruz, CA, USA) for 2 hours at room temperature and then washed with PBS plus $0.1 \%$ Tween 20 (PBS-T) 3 times at 10 minutes each time. The membrane was further incubated with goat anti-rabbit IgG HRP-conjugated secondary antibodies (Thermal Scientific, Rockford, IL, USA) for 1 hour followed by three washes with PBS-T. Chemiluminescence was assayed with an Amersham ECL ${ }^{\mathrm{Tu}}$ advance western blotting detection kit (GE Healthcare Biosciences, Piscataway, NJ, USA). GAPDH was used as an internal control.

\section{Real-time RT-qPCR}

Total RNA was extracted from cultured cells or mouse renal tissue using an RNeasy kit (Qiagen) and reversetranscribed into cDNA with Superscript III using random primer (Invitrogen). RT-qPCR were carried out using TaqMan assays on a 7900 real-time PCR system (Applied Biosystems, Foster City, CA, USA) with $5 \mu \mathrm{l}$ of $2 \times$ TaqMan Universal PCR Master Mix, $4.5 \mu \mathrm{l}$ of cDNA, and $0.5 \mu \mathrm{l} 20 \times$ TaqMan Gene Expression Assay Mix under the following thermal cycling conditions: $95^{\circ} \mathrm{C}$ for 10 minutes, followed by 40 cycles of $95^{\circ} \mathrm{C}$ for 15 seconds and $60^{\circ} \mathrm{C}$ for 1 minute. Each sample was run in triplicate. 18S rRNA (Hs03003631_g1) was used as an internal control. The TaqMan assay identification numbers of the genes measured are as follows: $B c l 2$ (Mm00477631_m1), CASP3 (Mm01195085_m1), CAT (Mm00437992_m1), CCL2 (Mm00441242_m1), CCL5 (Mm01302428_m1), CCL7 (Mm00443113_m1), CCR5 (Mm01216171_m1), CD40lg (Mm00441911_m1), Fasl (Mm00438864_m1), GPX1 (Mm00656767_g1), GSTM2 (Hs00265266_g1), IL-1 (Mm00434228_m1), IL-6 (Mm 99999064_m1), NFKB1 (Mm00476361_m1), TGF- $\beta_{2}$ (Mm00436952_m1), and TNF (Mm00443258_m1).

\section{Measurement of proteinuria and BUN}

Urine samples were collected for 24 hours from all the experimental mice using metabolic cages with mice allowed free access to water. Following the relevant manufacturer's instructions, urinary protein concentration was determined using a Coomassie Plus protein assay kit (Thermo Fisher Scientific, Rockford, IL, USA), while the serum BUN level was measured with a urea nitrogen kit (Sigma-Aldrich).

\section{Nitric oxide detection and antioxidase activity assay}

NO level in kidney was quantified by QuantiChrom Nitric Oxide Assay Kit (BioAassay Systems, Hayward, CA, USA). Briefly, the kidney tissue was homogenized in PBS and centrifuged at $10,000 \times g$ at $4^{\circ} \mathrm{C}$. The supernatant was firstly deproteinized by treating with $\mathrm{ZnSO}_{4}$ and $\mathrm{NaOH}$, then $200 \mu \mathrm{l}$ of working reagent was added to $100 \mu \mathrm{l}$ of sample and incubated at room temperature for $150 \mathrm{mi}$ nutes. Finally, the optical density (OD) of each reaction was read at $540 \mathrm{~nm}$. NO level was calculated based on a standard curve. SOD, and CAT activity in mouse kidney tissue were measured using relevant kits (SOD Assay Kit (Sigma-Aldrich) and Catalase Assay Kit (Cayman Chemical Company, Ann Arbor, MI, USA), following each manufacturer's instructions.

\section{Kidney morphological and histological analysis}

Renal tissues from mice were fixed in 10\% formaldehyde, dehydrated, embedded in paraffin wax, and sectioned. Tissue sections were stained with periodic acid Schiff (PAS), and examined in a blinded manner to evaluate the degree of nephritis. The severity of GN was graded on a scale of 0 to 4 . The severity of tubulointerstitial nephritis was also graded on a scale of 0 to 4 , based on the extent of tubular atrophy, inflammatory infiltrates, and interstitial fibrosis, as detailed previously [12]. The mesangial matrix accumulation was also evaluated by PAS staining. Immunohistochemical staining was performed to detect mesangial cell proliferation and monocyte/macrophage infiltration with specific antibodies. 


\section{Terminal dUTP nick-end labeling assay on kidney tissue sections}

Apoptosis detection in kidney tissue sections was performed with a DeadEnd $^{\mathrm{Tm}}$ Colorimetric Apoptosis Detection System (Promega Corporation, Madison, WI, USA) in accordance with the manufacturer's instructions. TUNEL-positive apoptotic cells were observed under light microscopy.

\section{Renal immunohistochemical analysis}

Immunohistochemical staining was performed on renal sections as described previously [19]. Infiltration of lymphocytes and macrophages was assayed by staining with anti-CD3 antibody (1:200 dilution; Thermo Fisher Scientific) and anti-Iba1 antibody (1:800 dilution; Abcam, Cambridge, MA, USA), respectively. The number of CD3positive and Iba1-positive cells was calculated in 20 high power fields (HPFs).

Levels of redox-related enzymes were also assayed by immunohistochemical staining using the following antibodies: anti-catalase (1:500; Sigma-Aldrich); anti-GPX1 (1:300) and anti-iNOS (1:200) (both Abcam). The kidney slides were stained using a biotin-free immunoenzymatic antigen detection system (Expose mouse/rabbit specific HRP/DAB IHC kit, Abcam, USA). The intensity of immunohistochemical staining signal for CAT, GPX1 and inducible nitric oxide synthase (iNOS) was evaluated using the scales described previously [20], and the positive cells were counted in 20 HPFs.

\section{Statistical analysis}

Data were analyzed by standard statistical methods, and Student's $t$-test was used in statistical evaluation of the data as appropriate using GraphPad Prism 5 (GraphPad Software, Inc., La Jolla, CA, USA). Group data are expressed as means \pm SEM. Values of all parameters were considered significantly different at a value of $P<0.05$.

\section{Results \\ GSTM2 expression increased in the kidney of anti-GBM- GN-resistant mice}

Our previous studies showed that different mouse strains had different sensitivity to anti-GBM-GN. NZW, DBA1, and 129/svj mice, which were sensitive to antiGBM-GN, exhibited severe nephritis, whereas B6 and $\mathrm{BALB} / \mathrm{c}$ mice, which were relatively resistant to antiGBM-GN, had very mild nephritis [17]. Microarray gene expression analysis was performed on the five mouse strains (data are shown in the supplementary material; see Additional file 1: Figure S1; see Additional file 2: Table S1; see Additional file 3: Table S2). Comparing the gene expression profile of the redox-related genes in the kidneys of the different strains identified a group of differentially expressed genes that clearly distinguished between anti-GBM-GN-sensitive and anti-GBM-GN- resistant strains (Figure 1A). Of these genes, the GSTM2 gene was found to be significantly increased in B6 and BALB/c mice compared with the three sensitive strains (Figure 1A). The microarray data were further confirmed by RT-qPCR assay (Figure 1B). GSTM2 is involved in detoxification of ROS [13], and was selected for further experiments in this study.

\section{hGSTM2-MSCs expressed hGSTM2, and maintained the differentiation property of MSCs}

The human GSTM2 gene coding region was amplified by PCR, and cloned into the MCSs of a lentiviral vector, pCDH-MSCV-MCS-EF1-GFP-Puro (Figure 2A). The recombinant viral particles, pCDH-hGSTM2, were purified from package cells and transduced into MSCs. Untransduced MSCs had a fibroblast-like spindle shape (Figure 2B). hGSTM2-transduced MSCs were GFP-positive under fluorescence microscopy (Figure 2C). hGSTM2 expression was assayed by RT-qPCR and western blotting; it was found only in hGSTM2-MSCs, and not in pCDH-MSCs (Figure 2D, E).

The cell growth curve of MSCs, pCDH-MSCs, and hGSTM2-MSCs is shown in Figure 3A; no significant difference in cell proliferation was observed between these three cell lines. The potential of MSCs to differentiate into osteocytes and adipocytes was examined by culturing the MSCs in appropriate induction medium. After 3 weeks of culture, the adipocytes were stained with Oil Red $\mathrm{O}$, and adipose droplets were visible (Figure $3 \mathrm{~B}$ ). In the undifferentiated control groups, the cells maintained their fibroblast-like shape without visible formation of lipid droplets. For osteogenic differentiation, nodule-like structures, which were stained with Alizarin red, were observed after 3 weeks of induction, as shown in Figure $3 \mathrm{C}$.

\section{hGSTM2-MSCs were more resistant to $\mathrm{H}_{2} \mathrm{O}_{2}$-induced apoptosis}

The anti-oxidant effect of hGSTM2-MSCs was evaluated for $\mathrm{H}_{2} \mathrm{O}_{2}$-induced apoptosis. Treatment with $0.5 \mathrm{mM}$ $\mathrm{H}_{2} \mathrm{O}_{2}$ for 6 hours induced a significant amount of apoptosis in MSCs and pCDH-MSCs (17\% and 18\% respectively) (Figure 4A, B), whereas the number of apoptotic cells in hGSTM2-MSCs was significantly reduced (11\%, $P<0.05$ ) (Figure $4 \mathrm{C}, \mathrm{D}$ ), indicating that hGSTM2-MSCs were more resistant to $\mathrm{H}_{2} \mathrm{O}_{2}$-induced apoptosis.

\section{hGSTM2-MSCs localized in mouse kidney and expressed hGSTM2}

We monitored the GFP signal of hGSTM2-MSCs; at 72 hours after tail vein injection, GFP-positive MSCs were found to have migrated and localized in the kidney tubular interstitial region of recipient mice (Figure 5A, B). Expression of hGSTM2 in mouse kidney was assayed by RT-qPCR and western blotting; it was found in the 

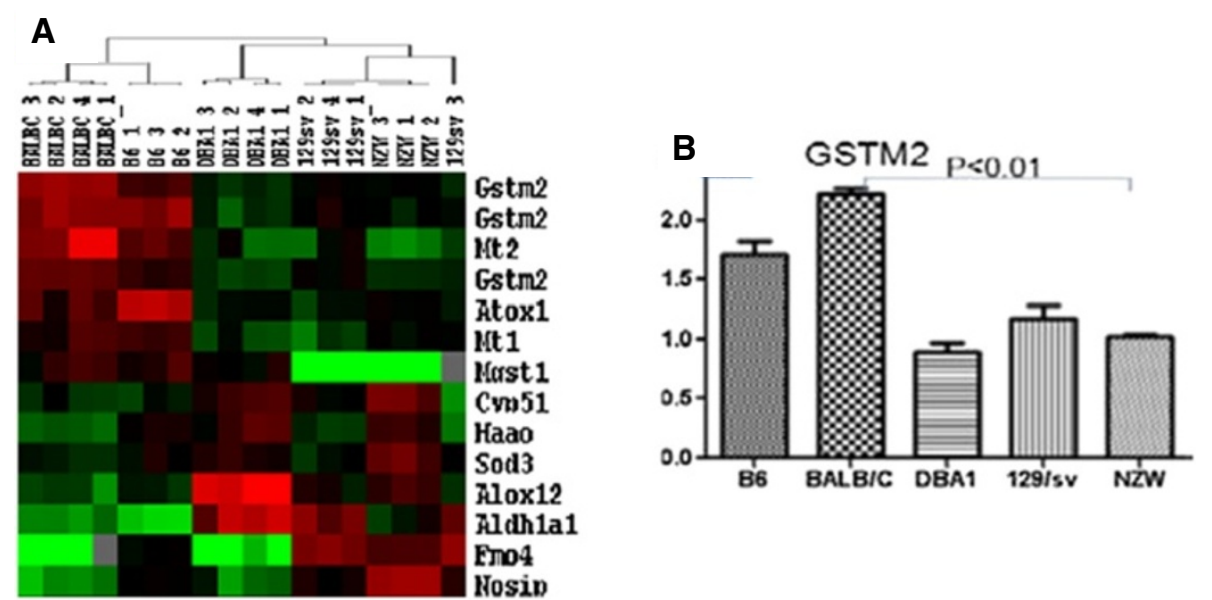

Figure 1 Kidney gene expression profiling of five mice strains in an anti-glomerular basement membrane antibody-induced glomerulonephritis (anti-GBM-GN) mouse model. (A) A group of oxidative stress-related genes that were differentially expressed between anti-GBM-GN-resistant mouse strains (B6 and BALB/C) and anti-GBM-GN-sensitive strains (DBA1, 129/svj, and NZW). The GSTM2 gene was up-regulated in anti-GBM-GNresistant strains compared with anti-GBM-GN-sensitive strains. (B) Expression of glutathione S-transferase Mu 2 (GSTM2) in different mouse strains was confirmed by reverse transcription quantitative PCR.

hGSTM2-MSC-injected mice, but not in the pCDHMSC-injected mice (Figure 5C and 5D).

\section{hGSTM2-MSCs attenuated anti-GBM-GN}

The protective effect of hGSTM2-MSCs on anti-GBMGN was assessed in 129/svj mice. Before anti-GBM challenge, all mice had basal levels of proteinuria (1.52 \pm $0.10 \mathrm{mg} / 24$ hours $)$ and BUN $(7.80 \pm 0.64 \mathrm{mg} / \mathrm{dL})$. At day 14 after anti-GBM challenge, both pCDH-MSCs and hGSTM2-MSCs injected mice exhibited dramatically increased levels of proteinuria and BUN (Figure 6A and $6 \mathrm{~B})$. However, compared with pCDH-MSC mice, the

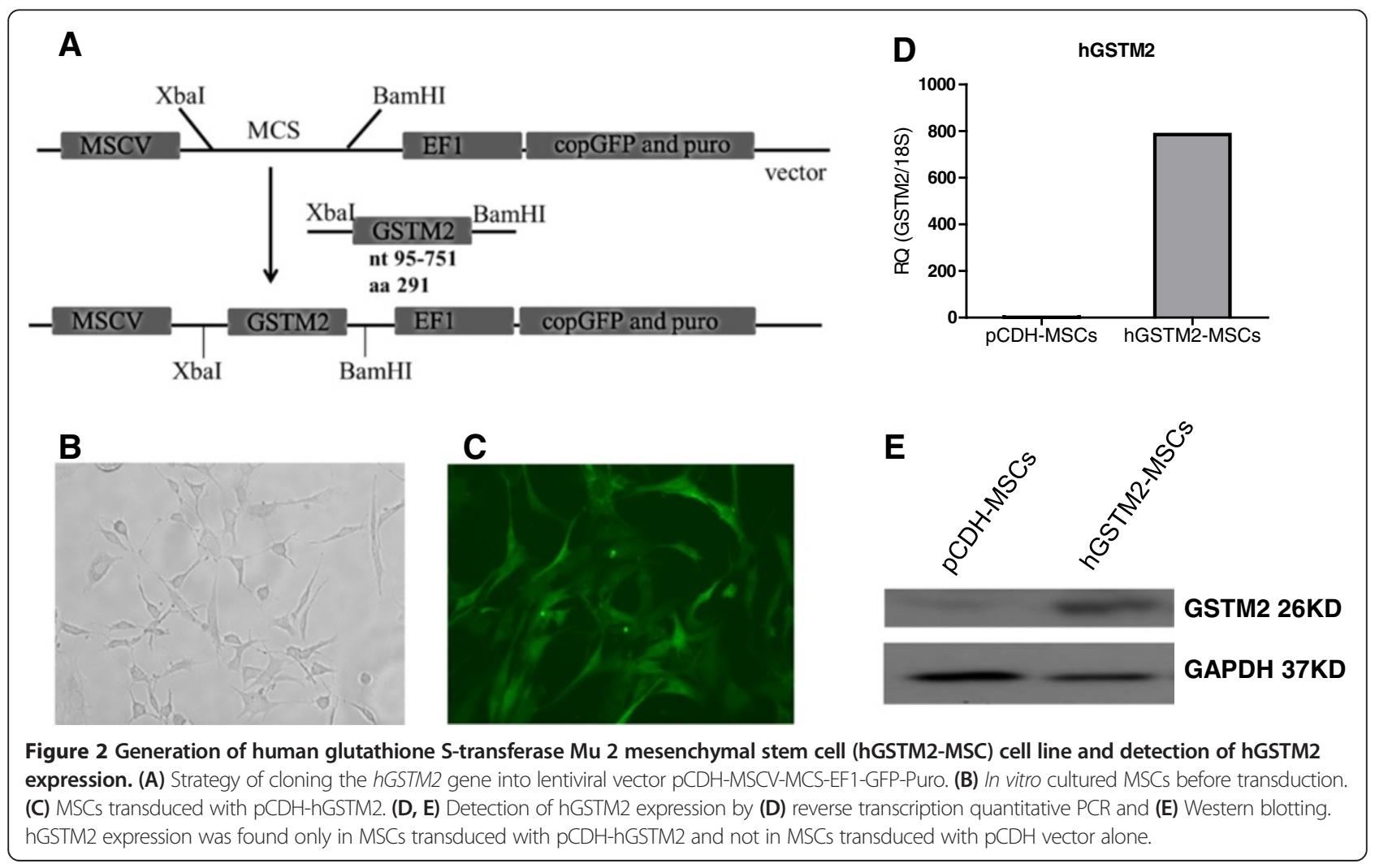



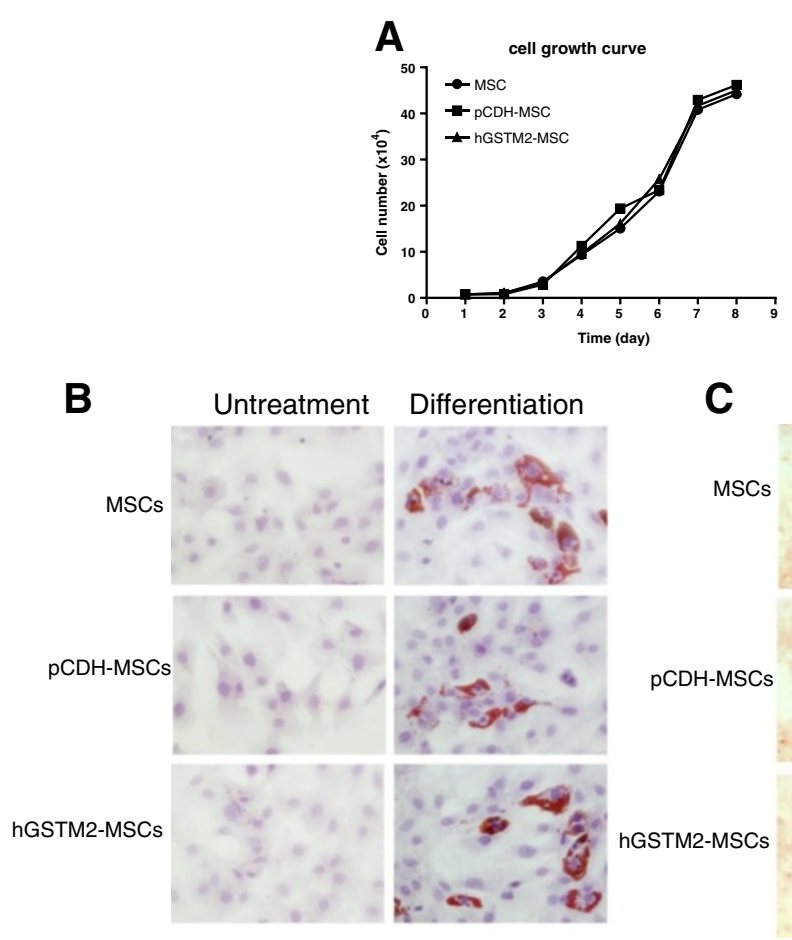

\section{Untreatment Differentiation}

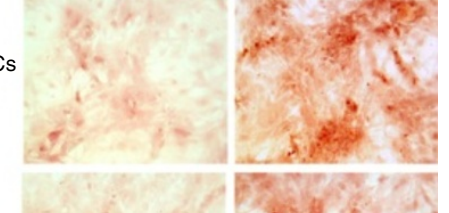

pCDH-MSCs

hGSTM2-MSCs

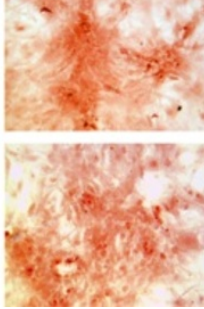

Figure 3 Mesenchymal stem cells (MSCs) proliferation and differentiation characterization. (A) Cell proliferation analysis on MSCs, pCDH-MSCs, and hGSTM2-MSCs. (B) The adipogenic differentiations of MSCs, PCDH-MSCs, and hGSTM2-MSCs were examined (at 21 days) with Oil Red O staining. (C) The osteogenic differentiations of MSCs, pCDH-MSCs, and hGSTM2-MSCs were examined (at 21 days) with Alizarin red staining (original magnification, $\times 200$ ).

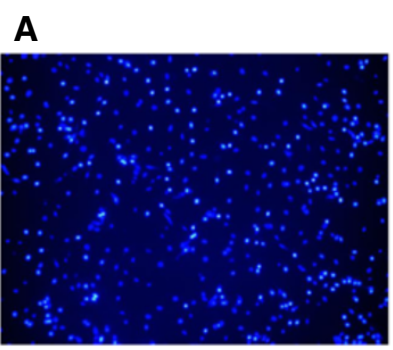

\section{B}

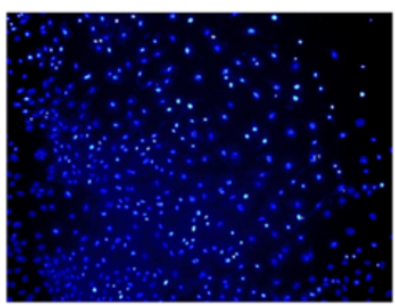

\section{D}

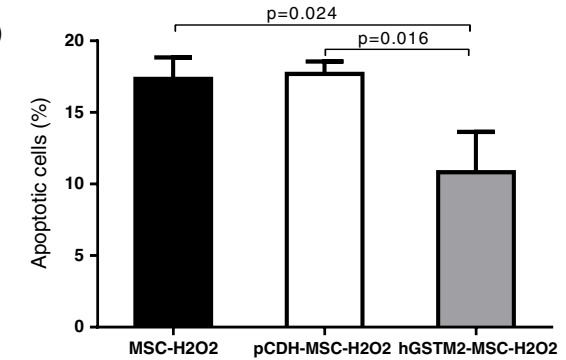

C

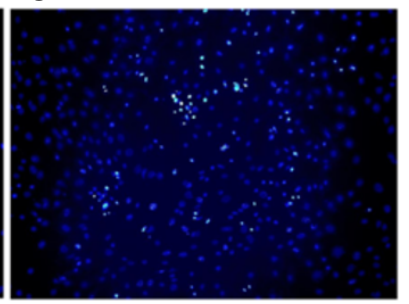

Figure 4 Human glutathione S-transferase Mu 2 mesenchymal stem cells (hGSTM2-MSCs) were resistant to hydrogen peroxide-induced apoptosis. (A-C) Detection of apoptotic cells by terminal dUTP nick-end labeling (TUNEL) staining on in vitro cultured MSCS treated with $0.5 \mathrm{mM}$ $\mathrm{H}_{2} \mathrm{O}_{2}$ for 6 hours: representative images from (A) untransduced MSCs, (B) pCDH-MSCs (vector controls), and (C) hGSTM2-MSCs. (D) Quantitative analysis of apoptotic cells showed that the percentage of apoptotic cells was significantly higher for MSCs and pCDH-MSCs than for hGSTM2-MSCs $(P<0.05)$. 
A

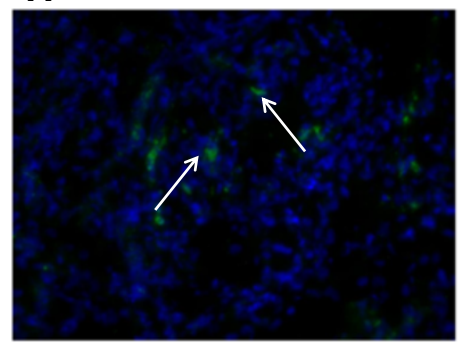

B

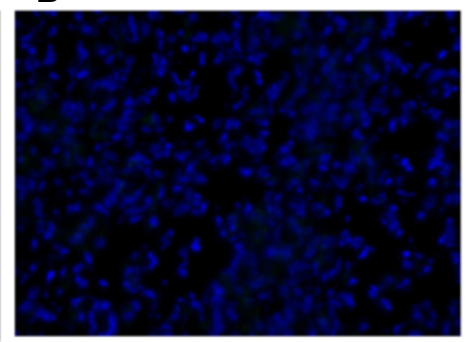

C

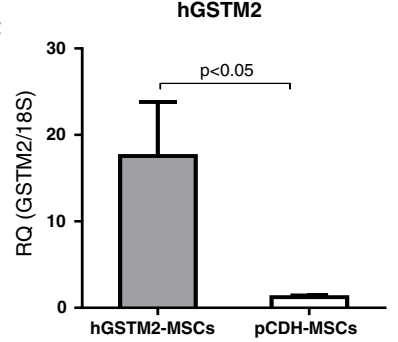

D

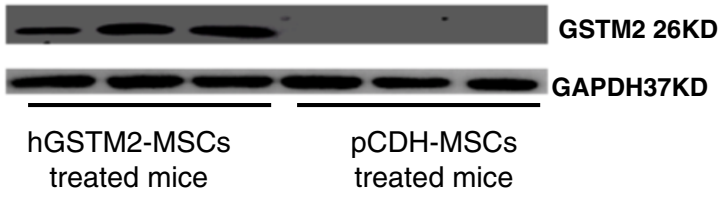

Figure 5 Human glutathione S-transferase Mu 2 mesenchymal stem cells (hGSTM2-MSCs) migrated to mouse kidney and expressed hGSTM2. (A) Assay of renal tubular and interstitial region of 129/svj mice after intravenous injection of pCDH-MSCs (vector control) or hGSTM2-MSCs. (B) Image of kidney from control mice receiving PBS injection. (C-D) Detection by (C) reverse transcription quantitative PCR and (D) Western blotting of hGSTM2 expression in the kidney of mice receiving injection of pCDH-MSCs or hGSTM2-MSCs injection ( $\mathrm{n}=3$ per group).

hGSTM2-MSC mice showed significantly lower proteinuria $(9.77 \pm 0.82 \mathrm{mg} / 24$ hours vs. $20.79 \pm 1.35 \mathrm{mg} / 24$ hours, a $53 \%$ reduction) and BUN $(18.30 \pm 2.19 \mathrm{mg} / \mathrm{dL}$ vs. $28.20 \pm 1.50 \mathrm{mg} / \mathrm{dL}$, a $35 \%$ reduction $)(P<0.05)$. At day 21, the pCDH-MSC mice still had high levels of proteinuria (20.01 $\pm 1.47 \mathrm{mg} / 24$ hours) and BUN (40.40 \pm $1.05 \mathrm{mg} / \mathrm{dL}$ ), whereas the hGSTM2-MSC mice showed further reduction in both proteinuria $(8.35 \pm 0.42 \mathrm{mg} / 24$ hours) and BUN (16.70 $\pm 3.05 \mathrm{mg} / \mathrm{dL})$, which were $59 \%$ and $58 \%$ lower than that in pCDH-MSC group $(P<0.05)$ (Figure 6A, B). Histopathological analysis of kidney tissue revealed significant glomerular proliferation and crescent formation with GN score of $3.0 \pm 0.4$ in $\mathrm{pCDH}$ MSC-injected mice (Figure 6C, E), whereas hGSTM2MSC-injected mice exhibited significantly $(P<0.05)$ less severe pathological changes, with GN score $1.8 \pm 0.3$ (Figure 6D, 6E). These functional manifestation and histological findings indicated that MSCs expressing hGSTM2 attenuated anti-GBM autoantibody-induced GN in $129 /$ svj mice.

\section{hGSTM2-MSCs inhibited anti-GBM-induced renal cell apoptosis}

Renal cell apoptosis was examined in kidney sections from mice receiving hGSTM2-MSC or pCDH-MSC transplantation. The percentage of renal apoptotic cells was significantly lower in the hGSTM2-MSC group $(9.5 \% \pm 0.5)$ compared with the $\mathrm{pCDH}-\mathrm{MSC}$ group
$(17.5 \% \pm 0.6) \quad(P<0.05) \quad$ (Figure $7 \mathrm{~A}-\mathrm{C})$, indicating that hGSTM2-MSCs attenuated renal cell apoptosis in antiGBM-GN. In addition, RT-qPCR showed that $B c l 2$ and CD4Olg were up-regulated in hGSTM2-MSC-treated mice (Figure 8), which may have contributed to the antiapoptotic effect of hGSTM2-MSCs in mouse kidney.

\section{hGSTM2-MSCs ameliorated inflammatory cell infiltration} Infiltration of macrophage and $\mathrm{T}$ lymphocytes in the renal glomerular and interstential regions were assayed by immunohistochemical staining with anti-Iba1 and anti-CD3 antibodies. The number of infiltrated macrophages (Iba1positive) in hGSTM2-MSC-injected mice was significantly less than in pCDH-MSC-injected control mice $(25 \pm 1$ vs. $36 \pm 2$ cells per $\mathrm{HPF}, P<0.05$ ) (Figure 9A-C). Similarly, the infiltrated $\mathrm{T}$ lymphocytes (CD3-positive) were also lower in hGSTM2-MSC-injected mice than in the pCDH-MSCinjected control mice $(14 \pm 1$ vs. $21 \pm 1$ cells per HPF, $P<0.05$ ) (Figure 9D-F). hGSTM2-MSC treatment reduced macrophage and $\mathrm{T}$ lymphocyte infiltration in renal tissues by $31 \%$ and $33 \%$, respectively, compared with pCDHMSC-treated controls.

\section{hGSTM2-MSCs suppressed renal oxidative reaction}

The effect of hGSTM2-MSCs against oxidative stress was tested by measuring the renal expression level and/ or activity of oxidation-related products (iNOS, NO, CAT, GPX1 and SOD). The hGSTM2-MSC-treated mice 


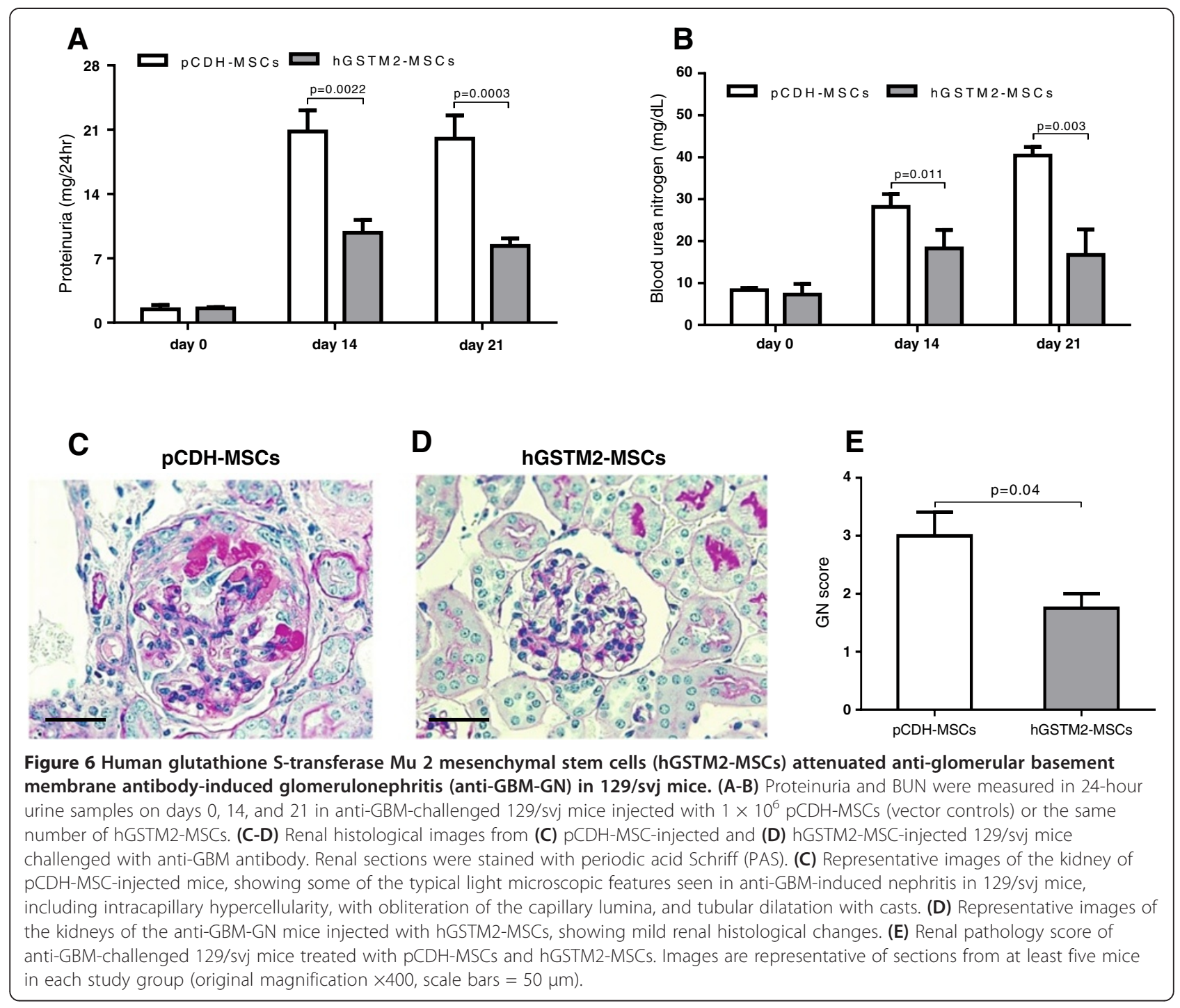

exhibited a significantly reduced number of iNOS-positive cells $(14 \pm 1$ cells/HPF) and lower level of NO (19.61 \pm $4.85 \mu \mathrm{M})$, which were approximately $39 \%$ and $66 \%$ lower than that in $\mathrm{pCDH}-\mathrm{MSC}$-injected controls $(23 \pm 2$ cells/ $\mathrm{HPF}$ and $57.25 \pm 12.79 \mu \mathrm{M}$, respectively, $\mathrm{P}<0.05$ in Figure $10 \mathrm{~A}$ and 10D). By contrast, the renal activity of SOD was significantly higher in hGSTM2-MSC-injected mice compared with pCDH-MSC-injected controls $(76.96 \pm 3.93$ vs. $59.52 \pm 4.48, P<0.05$ in Figure 10F). Furthermore, the number of CAT-positive and GPX1-positive cells was much higher in hGSTM2-MSC-injected mice (12 \pm 1 cells/HPF and $13 \pm 1$ cells/HPF), compared with pCDH-MSC-injected controls $(5 \pm 1$ cells/HPF and $4 \pm$ 1 cells/HPF, $P<0.05$ in Figure $10 \mathrm{~B}$ and 10C). CAT activity was further confirmed to be significantly higher in hGSTM2-MSC-injected mice compared with $\mathrm{pCDH}$ MSC-injected controls $(19.28 \pm 0.58 \mathrm{nmol} / \mathrm{min} / \mathrm{ml}$ vs. $12.32 \pm 1.43 \mathrm{nmol} / \mathrm{min} / \mathrm{ml}, P<0.05$ in Figure 10E).

\section{hGSTM2-MSCs inhibited inflammatory cytokines}

The levels of inflammatory cytokines were measured by RT-qPCR. As shown in Figure 8, the chemokine CCL2 and the cytokines $I L-1 \beta$ and $I L-6$ were decreased by $53 \%$, $46 \%$, and $52 \%$, respectively, in hGSTM2-MSC-injected mice compared with pCDH-MSC-injected controls $(P<0.05)$. Decreased expression of several other cytokines, including CASP3, CCL5, CCL7, Fasl and TNF, was also found in mice transplanted with hGSTM2-MSCs, although this was not statistically significant compared with controls (data not shown).

\section{Discussion}

It is well known that inflammatory cytokines and chemokines are involved in the pathogenesis of immunemediated nephritis [21,22]. Immune-mediated nephritis is an autoimmune and inflammatory process involving immune cell infiltration and expression of inflammatory 

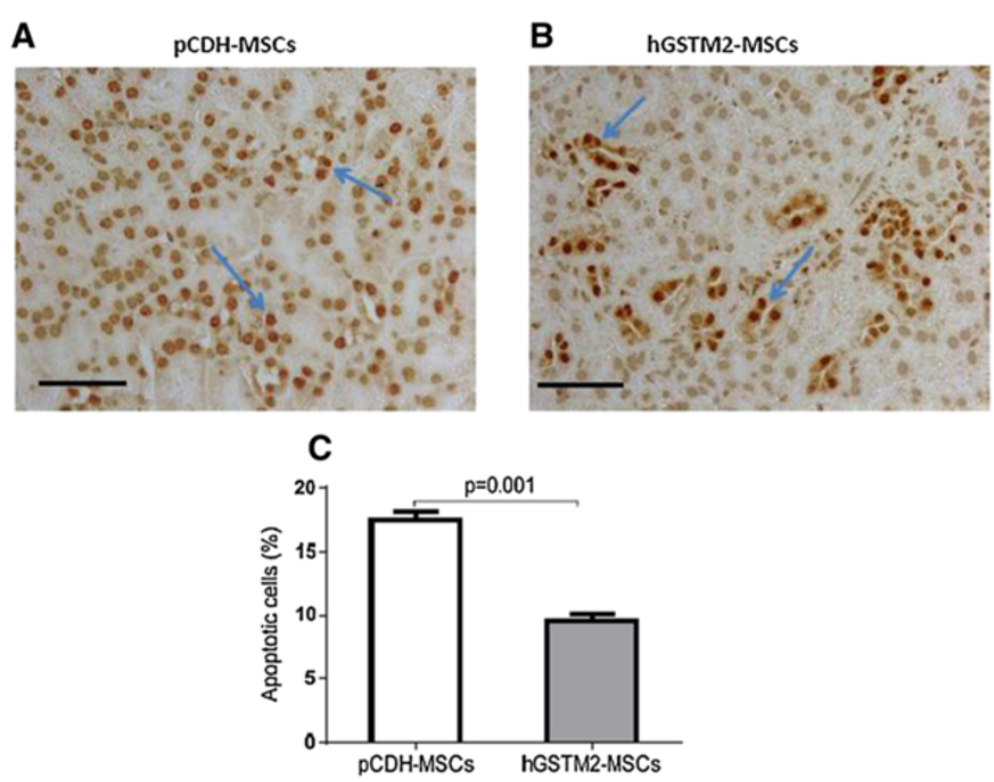

Figure 7 Human glutathione S-transferase Mu 2 mesenchymal stem cells (hGSTM2-MSCs) inhibited renal cell apoptosis in anti-glomerular basement membrane antibody-induced glomerulonephritis (anti-GBM-GN) mice. Terminal dUTP nick-end labeling (TUNEL) staining using DeadEnd ${ }^{\mathrm{TM}}$ Colorimetric Apoptosis Detection System to show apoptotic cells in renal sections of 129/svj with anti-GBM-GN injected with (A) pCDH-MSCs (vector control) or (B) hGSTM2-MSCs. Cells with brown nuclei are apoptotic cells (indicated by arrow). (C) Quantitative analysis of apoptotic cells expressed as a percentage of total cell number. Images were representative of sections from at least five mice in each study group (original magnification $\times 400$, scale bars $=50 \mu \mathrm{m}$ ).

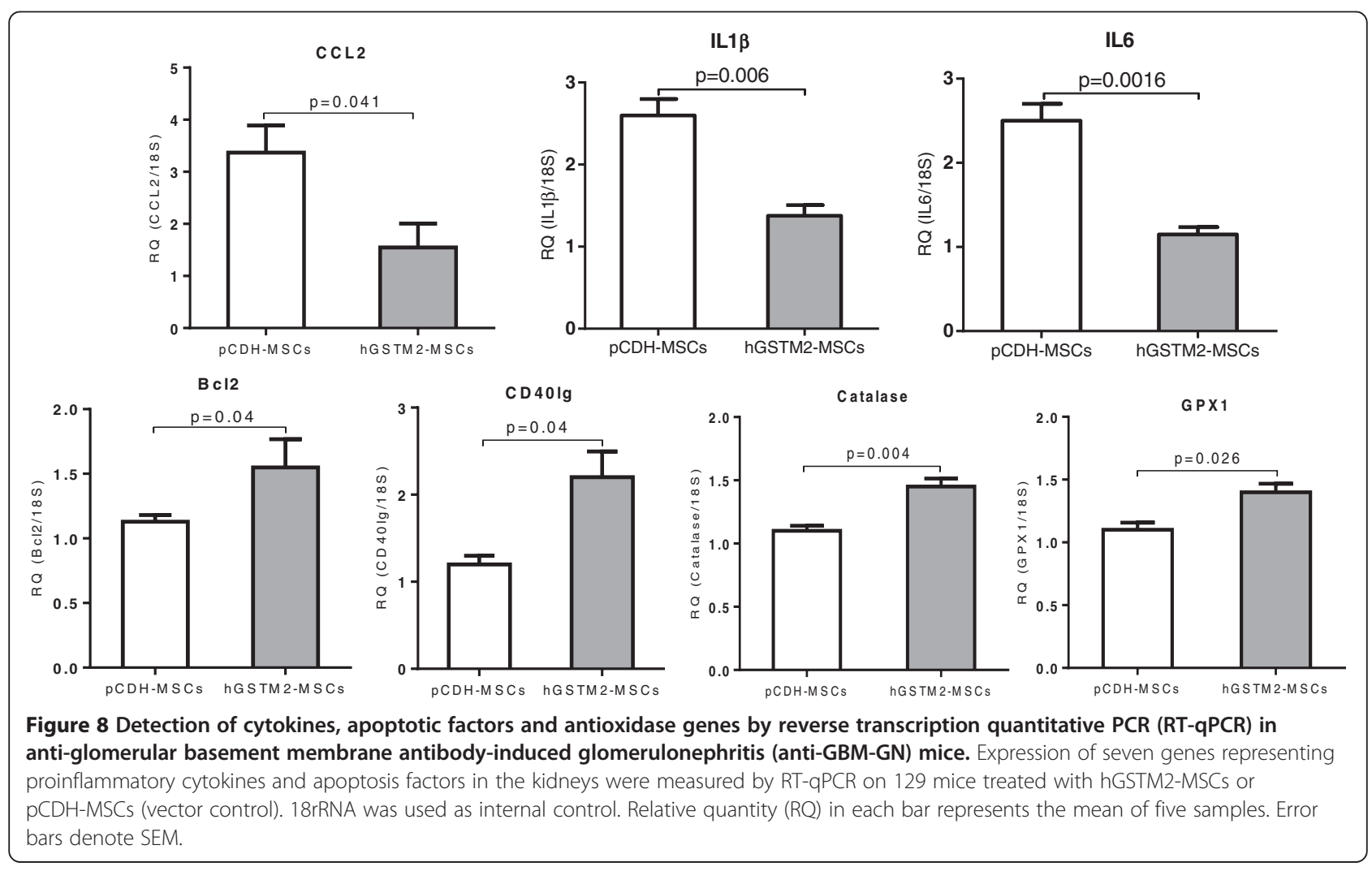




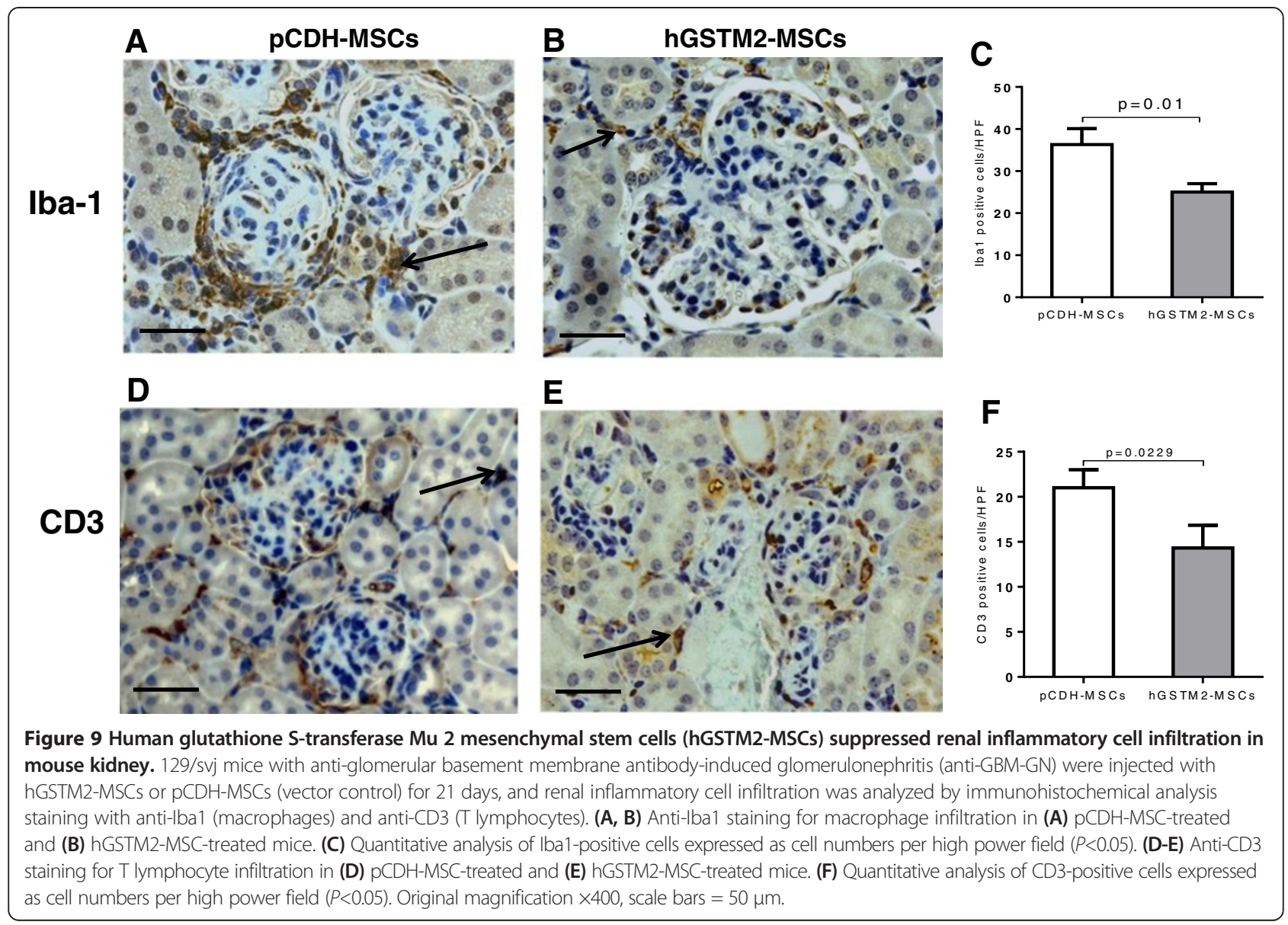

chemokines [23-26]. During the process of inflammation, the activated inflammatory reaction leads to the generation of oxidative radicals, such as $\mathrm{H}_{2} \mathrm{O}_{2}$ and ROS, and accumulation of these radicals will cause tissue damage. Excessive ROS can disturb redox status, resulting in damage to macromolecules, and can modulate the expression of a variety of immune and inflammatory molecules, further exacerbating inflammation and inducing tissue damage [27]. Further studies have shown the presence of increased oxidative stress in chronic kidney disease [28-30]. These observations implicate the relationship between ROS and chemotactic cytokine production in autoimmune disease.

In the study, using the anti-GBM-GN mouse model, we found that the increased sensitivity of 129 /svj mice to anti-GBM antibody-induced renal damage may be related to impaired production of the anti-oxidant molecule GSTM2 in inflamed renal tubules. Therefore, we postulated that manipulating the expression of GSTM2 in mouse kidney might be able to combat the renal injury caused by anti-GBM antibodies.

In order to target GSTM2 expression in inflamed kidneys, we chose to use genetically modified MSCs as vehicles. MSCs have been shown to be a promising approach for targeted gene delivery because of their potential to migrate to the injured renal tissue and differentiate into intrinsic kidney cells [31,32]. Genetically modified MSCs have been used to carry kallikrein (KLK), HO-1 and PEDF genes, which showed increased protective effect against acute ischemic kidney injury, osteoporosis, and hepatocellular carcinoma, respectively [33-35]. We recently further proved that KLK-transduced MSCs exhibited enhanced protective effect against antiGBM-GN and lupus nephritis [36]. The molecular pathways underlining the protective effect of KLK in anti-GBMGN is not yet fully understood, but the close correlation between the levels of KLK and GSTM2 in the renal tissue of anti-GBM-GN mice implies that GSTM2 might be one of the effector molecules involved in ameliorating inflammation and oxidative stress during the course of autoantibody-induced nephritis $[17,18,36,37]$.

In the current study, we used lentiviral vector, an efficient and safe retroviral vector system to transduce the human GSTM2 gene into mouse MSC genome. This vector carries GFP and a drug-resistant selection marker, which facilitate the cloning process. Furthermore, we 


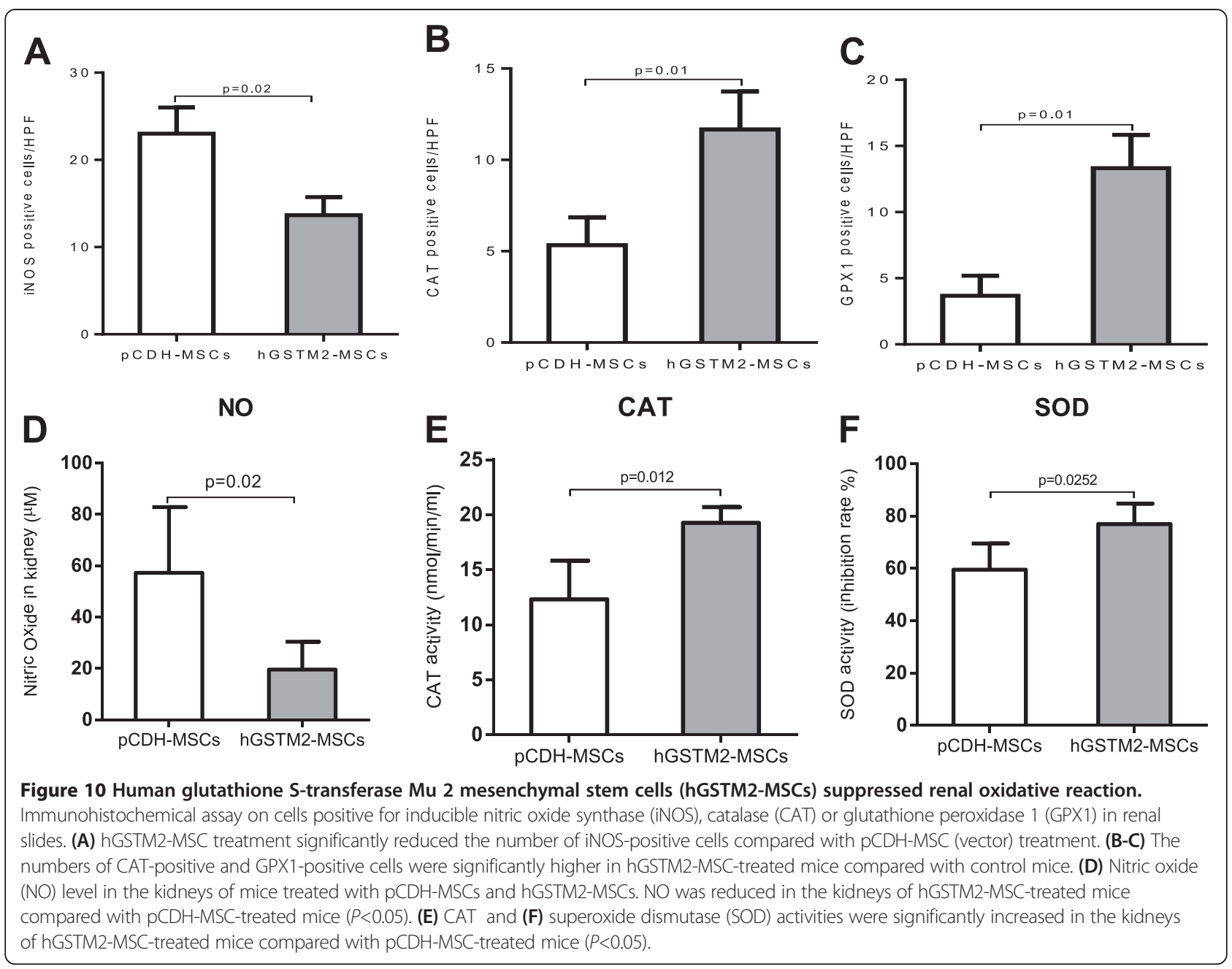

used human GSTM2 instead of the mouse gene, to allow easy monitoring of hGSTM2 expression in mouse tissues. The stable cell line, hGSTM2-MSC, not only expressed high levels of hGSTM2, but also retained the differentiation properties of MSCs. After transplantation into 129 /svj mice, the hGMTM2-MSCs migrated to the kidney and expressed high levels of hGSTM2 locally.

We tested the anti-oxidant effect of hGSTM2 in vitro by $\mathrm{H}_{2} \mathrm{O}_{2}$ stimulation assay. The data showed that hGSTM2-transduced MSCs (hGSTM2-MSCs) were more resistant to $\mathrm{H}_{2} \mathrm{O}_{2}$-induced apoptosis compared with vector-transduced MSCs (pCDH-MSCs). A similar effect was observed in vivo in mouse kidneys. The hGSTM2MSC-injected mice exhibited much less renal cell apoptosis than the pCDH-MSC-treated controls. The anti-apoptotic effect of GSTM2 is possibly attributable to its ability to erase oxidative radicals by detoxifying ROS and superoxide [13]. It was reported that GSTM2 could inhibit oxidative damage and inflammation [13-16], and it was shown that ROS is a source of cell stress and apoptosis [8]. hGSTM2-MSC injection inhibited the activity of renal iNOS, which is a major source of reactive oxidant stress in murine models of lupus nephritis [38]. We observed that the expression of GSTM2 in hGSTM2MSC-treated mice was accompanied by over-expression of CAT and GPX1, which are both potential scavengers of free oxidative radicals. The anti-apoptotic effects of the oxidation-resistant genes may be related to the increase in anti-apoptotic molecules such as $\mathrm{Bcl} 2$ and CD40lg $[39,40]$, which were significantly up-regulated in hGSTM2-MSC-treated mouse kidneys.

The main function of GSTs involves cellular detoxification, and this detoxification process is a critical cellular defense mechanism, which can protect the cell against a series of toxic and chemical substances [41]. Although normal cells can deal with oxidative stress through intact anti-oxidative systems, GSTs and GPXs prevent the cells from further oxidative damage [42]. If the oxidative stress exceeds a defendable level or if there is a dysfunction of the cellular anti-oxidative system, the exogenous and endogenous oxidative stresses will cause oxidative damage to tissue. The ability to 
withstand toxic chemicals and oxidative stress is essential for the survival of all organisms, thus disruption of these redox circuits will cause oxidative stress, and even oxidative damage.

A reduction in the activity of CAT in serum was found in anti-GBM-GN, and a significant decrease in the activity of GPX was observed in patients with systemic lupus erythematosus (SLE) [19,26]. A change in redox ratio is a significant parameter for oxidative stress and such as change in favor of oxidized glutathione is observed in autoimmune disease. The levels of glutathione correlate negatively with disease activity in SLE. Low levels of glutathione have also been found in the majority of patients with SLE patients who have nephritis [26]. It has been suggested that the reduced activities of CAT and GPX in nephritis could be due to the inactivation of the enzymes by over-generation of $\mathrm{H}_{2} \mathrm{O}_{2}$ [43]. GPX1 is one of the main cytosolic isoforms in mammalian cells, and plays a crucial role in the protection of cells against oxidative damage by $\mathrm{H}_{2} \mathrm{O}_{2}$ [44]. GPXs, as major anti-oxidative damage enzymes, can protect cells against oxidative damage [45]. The primary role of GST is the metabolism of a broad range of ROS, and it thus plays an important role in cellular resistance against oxidative stress [46].

Oxidative stress and inflammation are two closely related pathological processes in immune-mediated tissue damage $[26,47,48]$. Deposition of autoantibody and/or immune complex can initiate a local immune response involving complement activation, immune cell infiltration, and inflammatory cytokine secretion. The inflammation process that recruits $\mathrm{T}$ cells, $\mathrm{B}$ cells, macrophages, and neutrophils to the inflammatory sites could generate excessive free ROS and superoxide, which will then accelerate the immunological damage in lupus nephritis. In this report, we observed that hGSTM2-MSCs suppressed the expression of inflammatory cytokines, and inhibited infiltration of lymphocytes and macrophages in renal tissues, further confirming that suppression of oxidative stress can ameliorate inflammatory damage.

Previous experiments have shown that MSCs themselves might be a therapeutic source for treatment of immune-related renal disease including lupus nephritis $[49,50]$. Our data indicate that transducing MSCs with therapeutic genes could significantly enhance their effect on anti-GBM-GN and lupus nephritis [36]. This study provides further evidence that MSCs could be used as vehicles to deliver potential therapeutic molecules to target tissues, and therefore may have an added beneficial effect on immune-medicated renal disease.

We plan to perform further experiments to evaluate the protective effect of hGSTM2-MSCs on lupus nephritis and diabetic nephritis, as both diseases show chronic renal inflammation. Further experiments should also be conducted to evaluate the distribution and expression of target gene in other tissues, and the longterm effect of transplanted cells, before they are trialed for treatment of human diseases.

\section{Conclusions}

GSTM2 might be an important player in combating anti-GBM-GN. hGSTM2-MSCs suppressed the expression of inflammatory cytokines and inhibited infiltration of lymphocytes and macrophages in renal tissues, which may have contributed to the suppression of oxidative stress and amelioration of inflammatory damage. Thus, GSTM2-transduced MSCs may be a potential therapeutic agent for immune-mediated nephritis.

\section{Additional files}

\begin{abstract}
Additional file 1: Figure S1. Expression of oxidation-related genes in the kidney cortex of five mouse strains. (A) Heatmap using DNA microarray of the expression value of oxidation-related genes in five mouse strains after anti-glomerular basement membrane antibodyinduced glomerulonephritis (anti-GBM) challenge. Red represents upregulation, and green represents down-regulation. (B-F) Quantitative PCR confirmation of the expression of five representative genes in different mice strains after anti-GBM challenge. $R Q$, relative quantity. Three mice were used per group.
\end{abstract}

Additional file 2: Table S1. Transcriptomic analysis by DNA microarray of gene expression in kidneys of different mouse strains after antiglomerular basement membrane antibody-induced glomerulonephritis (anti-GBM) challenge.

Additional file 3: Table S2. The mRNA expression level of 15 oxidation-related genes in kidneys of five strains of mice after anti-glomerular basement membrane antibody-induced glomerulonephritis (anti-GBM) challenge.

\section{Abbreviations}

BCl2: B cell leukemia/lymphoma; BUN: Blood urea nitrogen; CASP3: caspase 3; CAT: Catalase; CCL2: chemokine (C-C motif) ligand 2; CCL5: chemokine (C-C motif) ligand 5; CCL7: chemokine ( $C-C$ motif) ligand 7; CCR5: chemokine (C-C motif) receptor 5; CD40lg: CD40 ligand; DMEM: Dulbecco's modified Eagle's medium; Fasl: Fas ligand; GBM-GN: Glomerular basement membrane antibody-induced glomerulonephritis; GFP: Green fluorescent protein; GPX: Glutathione peroxidase; GPX1: glutathione peroxidase 1; GST: Glutathione S-transferases; GSTM2: glutathione S-transferase Mu 2; HO1: heme oxygenase-1; HRP: horseradish peroxidase; IL-1 $\beta$ : interleukin 1 beta; IL-6: interleukin 6; iNOS: inducible nitric oxide synthase; KLK: kallikrein; MSC: Mesenchymal stem cells; MCSs: multiple cloning sites; NFkB1: nuclear factor of kappa light polypeptide gene enhancer in B cells 1; PAS: periodic acid Schiff; PBS-T: Phosphate-buffered saline with Tween; PEDF: pigment epithelium-derived factor; PVDF: polyvinylidene fluoride; ROS: Reactive oxygen species; SLE: Systemic lupus erythematosus; SOD: Superoxide dismutase; TGF- $\beta 2$ : transforming growth factor, beta 2; TNF: tumor necrosis factor; TUNEL: terminal dUTP nick-end labeling.

\section{Competing interests}

All the authors declared no conflict of interest.

\section{Authors' contributions}

$Y L$ participated in the experimental design, performed the experiments, collected data, and drafted the manuscript. MY and YD performed animal experiments and sample analysis. JY performed data analysis. IR and SM performed stem cell isolation and cell culture. XF and CM participated in the design and coordination of the study. QL conceived the study, designed the experiments, and finalized the manuscript. All authors read and approved the final manuscript. 


\section{Acknowledgements}

We thank the UT Southwestern Microarray Core for assistance with microarray and GPCR experiments. This work was supported by National Institutes of Health grants P50 CORT AR055503 and R03 AR055778; National Natural Science Foundation of China (grant numbers 81070611 and 81270852)

\section{Author details}

${ }^{1}$ Department of Immunology and Internal Medicine, University of Texas Southwestern Medical Center, 5323 Harry Hines Blvd, Dallas, TX 75390-8814, USA. 'Laboratory of Disease Genomics and Individualized Medicine, Key Laboratory of Genome Sciences and Information, Beijing Institute of Genomics, Chinese Academy of Sciences, Beijing 100101, China. ${ }^{3}$ Division of Biostatistics, Department of Clinical Sciences, University of Texas Southwestern Medical Center at Dallas, Dallas, TX 75390, USA. ${ }^{4}$ Biomedical Engineering Department, University of Houston, Houston, TX 77204, USA. ${ }^{5}$ Key Laboratory of Medical Genetics, Wenzhou Medical University School of Laboratory Medicine and Life Science, Wenzhou 325035, China.

Received: 5 July 2013 Revised: 12 November 2013

Accepted: 15 January 2014 Published: 30 January 2014

\section{References}

1. Kambham N: Crescentic Glomerulonephritis: an update on Pauci-immune and Anti-GBM diseases. Adv Anat Pathol 2012, 19:111-124.

2. Borza DB, Neilson EG, Hudson BG: Pathogenesis of Goodpasture syndrome: a molecular perspective. Semin Nephrol 2003, 23:522-531.

3. Suzuki Y, Shirato I, Okumura K, Ravetch JV, Takai T, Tomino Y, Ra C: Distinct contribution of Fc receptors and angiotensin II-dependent pathways in anti-GBM glomerulonephritis. Kidney Int 1998, 54:1166-1174.

4. Little MA, Pusey CD: Rapidly progressive glomerulonephritis: current and evolving treatment strategies. J Nephrol 2004, 17:S10-S19.

5. Feng $L, X i a ~ Y$, Seiffert D, Wilson CB: Oxidative stress-inducible protein tyrosine phosphatase in glomerulonephritis. Kidney Int 1995, 48:1920-1928.

6. Kanaguchi $Y$, Suzuki Y, Osaki K, Sugaya T, Horikoshi S, Tomino Y: Protective effects of L-type fatty acid-binding protein (L-FABP) in proximal tubular cells against glomerular injury in anti-GBM antibodymediated glomerulonephritis. Nephrol Dial Transplant 2011, 26:3465-3473.

7. Ferguson MA, Vaidya VS, Waikar SS, Collings FB, Sunderland KE, Gioules CJ, Bonventre JV: Urinary liver-type fatty acid-binding protein predicts adverse outcomes in acute kidney injury. Kidney Int 2010, 77:708-714.

8. Valko M, Leibfritz D, Moncol J, Cronin MT, Mazur M, Telser J: Free radicals and antioxidants in normal physiological functions and human disease. Int J Biochem Cell Biol 2007, 39:44-84.

9. Rehan A, Johnson KJ, Wiggins RC, Kunkel RG, Ward PA: Evidence for the role of oxygen radicals in acute nephrotoxic nephritis. Lab Invest 1984 51:396-403.

10. Shah SV, Baliga R, Rajapurkar M, Fonseca VA: Oxidants in chronic kidney disease. J Am Soc Nephrol 2007, 18:16-28.

11. Xie C, Liu K, Fu Y, Qin X, Jonnala G, Wang T, Wang HW, Maldonado M, Zhou XJ, Mohan C: RANTES deficiency attenuates autoantibody-induced glomerulonephritis. J Clin Immunol 2011, 31:128-135.

12. Xie C, Sharma R, Wang H, Zhou XJ, Mohan C: Strain distribution pattern of susceptibility to immune-mediated nephritis. J Immunol 2004 172:5047-5055.

13. Zhou SG, Wang P, Pi RB, Gao J, Fu JJ, Fang J, Qin J, Zhang HJ, Li RF, Chen SR, Tang FT, Liu PQ: Reduced expression of GSTM2 and increased oxidative stress in spontaneously hypertensive rat. Mol Cell Biochem 2008, 309:99-107

14. Berliner JA, Navab M, Fogelman AM, Frank JS, Demer LL, Edwards PA, Watson AD, Lusis AJ: Atherosclerosis: basic mechanisms. Oxidation, inflammation, and genetics. Circulation 1995, 91:2488-2496.

15. Hayek T, Stephens JW, Hubbart CS, Acharya J, Caslake MJ, Hawe E, Miller GJ, Hurel SJ, Humphries SE: A common variant in the glutathione S transferase gene is associated with elevated markers of inflammation and lipid peroxidation in subjects with diabetes mellitus. Atherosclerosis 2006, 184:404-412

16. Strange RC, Jones PW, Fryer AA: Glutathione S-transferase: genetics and role in toxicology. Toxicol Lett 2000, 112-113:357-363.
17. Liu K, Li QZ, Delgado-Vega AM, Abelson AK, Sanchez E, Kelly JA, Li L, Liu Y, Zhou J, Yan M, Ye Q, Liu S, Xie C, Zhou XJ, Chung SA, Pons-Estel B, Witte T, de Ramon E, Bae SC, Barizzone N, Sebastiani GD, Merrill JT, Gregersen PK, Gilkeson GG, Kimberly RP, Vyse TJ, Kim I, D'Alfonso S, Martin J, Harley JB, et al: Kallikrein genes are associated with lupus and glomerular basement membrane-specific antibody-induced nephritis in mice and humans. J Clin Invest 2009, 119:911-923.

18. Li QZ, Zhou J, Yang R, Yan M, Ye Q, Liu K, Liu S, Shao X, Li L, Zhou XJ, Wakeland EK, Mohan C: The lupus-susceptibility gene kallikrein downmodulates antibody-mediated glomerulonephritis. Genes Immun 2009, 10:503-508

19. Lu H, Zhen J, Wu T, Peng A, Ye T, Wang T, Yu X, Vaziri ND, Mohan C, Zhou $\mathrm{XJ}$ : Superoxide dismutase mimetic drug tempol aggravates anti-GBM antibody-induced glomerulonephritis in mice. Am J Physiol Renal Physiol 2010, 299:F445-F452.

20. Zhou XJ, Laszik Z, Wang XQ, Silva FG, Vaziri ND: Association of renal injury with increased oxygen free radical activity and altered nitric oxide metabolism in chronic experimental hemosiderosis. Lab Invest 2000 80:1905-1914

21. Paust HJ, Turner JE, Riedel JH, Disteldorf E, Peters A, Schmidt T, Krebs C, Velden J, Mittrucker HW, Steinmetz OM, Stahl RA, Panzer U: Chemokines play a critical role in the cross-regulation of Th1 and Th17 immune responses in murine crescentic glomerulonephritis. Kidney Int 2012, 82:72-83.

22. Sheryanna A, Bhangal G, McDaid J, Smith J, Manning A, Foxwell BM, Feldmann M, Cook HT, Pusey CD, Tam FW: Inhibition of p38 mitogenactivated protein kinase is effective in the treatment of experimental crescentic glomerulonephritis and suppresses monocyte chemoattractant protein-1 but not IL-1beta or IL-6. J Am Soc Nephrol 2007, 18:1167-1179.

23. de Zubiria Salgado A, Herrera-Diaz C: Lupus nephritis: an overview of recent findings. Autoimmune Dis 2012, 2012:849684.

24. Schmitt N, Morita R, Bourdery L, Bentebibel SE, Zurawski SM, Banchereau J, Ueno $\mathrm{H}$ : Human dendritic cells induce the differentiation of interleukin21-producing $\mathrm{T}$ follicular helper-like cells through interleukin-12. Immunity 2009, 31:158-169.

25. Calvani N, Tucci M, Richards HB, Tartaglia P, Silvestris F: Th1 cytokines in the pathogenesis of lupus nephritis: the role of IL-18. Autoimmun Rev 2005, 4:542-548.

26. Shah D, Wanchu A, Bhatnagar A: Interaction between oxidative stress and chemokines: possible pathogenic role in systemic lupus erythematosus and rheumatoid arthritis. Immunobiology 2011, 216:1010-1017.

27. Kurien BT, Scofield RH: Autoimmunity and oxidatively modified autoantigens. Autoimmun Rev 2008, 7:567-573.

28. Vaziri ND: Roles of oxidative stress and antioxidant therapy in chronic kidney disease and hypertension. Curr Opin Nephrol Hypertens 2004, 13:93-99.

29. Oberg BP, McMenamin E, Lucas FL, McMonagle E, Morrow J, Ikizler TA, Himmelfarb J: Increased prevalence of oxidant stress and inflammation in patients with moderate to severe chronic kidney disease. Kidney Int 2004, 65:1009-1016.

30. Shah SV: Oxidants and iron in chronic kidney disease. Kidney Int Supp/ 2004, 91:S50-S55.

31. Lange C, Togel F, Ittrich H, Clayton F, Nolte-Ernsting C, Zander AR, Westenfelder C: Administered mesenchymal stem cells enhance recovery from ischemia/reperfusion-induced acute renal failure in rats. Kidney Int 2005, 68:1613-1617.

32. Togel F, Hu Z, Weiss K, Isaac J, Lange C, Westenfelder C: Administered mesenchymal stem cells protect against ischemic acute renal failure through differentiation-independent mechanisms. Am J Physiol Renal Physiol 2005, 289:F31-F42.

33. Hagiwara M, Shen B, Chao L, Chao J: Kallikrein-modified mesenchymal stem cell implantation provides enhanced protection against acute ischemic kidney injury by inhibiting apoptosis and inflammation. Hum Gene Ther 2008, 19:807-819.

34. Vanella L, Kim DH, Asprinio D, Peterson SJ, Barbagallo I, Vanella A, Goldstein D, Ikehara S, Kappas A, Abraham NG: HO-1 expression increases mesenchymal stem cell-derived osteoblasts but decreases adipocyte lineage. Bone 2010, 46:236-243.

35. Gao Y, Yao A, Zhang W, Lu S, Yu Y, Deng L, Yin A, Xia Y, Sun B, Wang X: Human mesenchymal stem cells overexpressing pigment epitheliumderived factor inhibit hepatocellular carcinoma in nude mice. Oncogene 2010, 29:2784-2794. 
36. Li Y, Raman I, Du Y, Yan M, Min S, Yang J, Fang X, Li W, Lu J, Zhou XJ, Mohan C, Li QZ: Kallikrein transduced mesenchymal stem cells protect against anti-GBM disease and lupus nephritis by ameliorating inflammation and oxidative stress. PLoS One 2013, 8:e67790.

37. Shao X, Yang R, Yan M, Li Y, Du Y, Raman I, Zhang B, Wakeland EK, Igarashi P, Mohan C, Li QZ: Inducible expression of kallikrein in renal tubular cells protects mice against spontaneous lupus nephritis. Arthritis Rheum 2013, 65:780-791.

38. Njoku CJ, Patrick KS, Ruiz P Jr, Oates JC: Inducible nitric oxide synthase inhibitors reduce urinary markers of systemic oxidant stress in murine proliferative lupus nephritis. J Investig Med 2005, 53:347-352.

39. Jones RL, Pepling ME: Role of the Anti-Apoptotic Proteins BCL2 and MCL1 in the Neonatal Mouse Ovary. Biol Reprod 2013, 88:46.

40. Jin X, Wu XX, Jin C, Inui M, Sugimoto M, Kakehi Y: Delineation of apoptotic genes for synergistic apoptosis of lexatumumab and anthracyclines in human renal cell carcinoma cells by polymerase chain reaction array. Anticancer Drugs 2012, 23:445-454.

41. Hansson LO, Bolton-Grob R, Massoud T, Mannervik B: Evolution of differential substrate specificities in Mu class glutathione transferases probed by DNA shuffling. J Mol Biol 1999, 287:265-276.

42. Dusinska M, Staruchova M, Horska A, Smolkova B, Collins A, Bonassi S, Volkovova K: Are glutathione $S$ transferases involved in DNA damage signalling? Interactions with DNA damage and repair revealed from molecular epidemiology studies. Mutat Res 2012, 736:130-137.

43. Ortona E, Margutti P, Matarrese P, Franconi F, Malorni W: Redox state, cell death and autoimmune diseases: a gender perspective. Autoimmun Rev 2008, 7:579-584.

44. Kokoszka JE, Coskun P, Esposito LA, Wallace DC: Increased mitochondrial oxidative stress in the Sod2 (+/-) mouse results in the age-related decline of mitochondrial function culminating in increased apoptosis. Proc Natl Acad Sci U S A 2001, 98:2278-2283.

45. Miyamoto Y, Koh YH, Park YS, Fujiwara N, Sakiyama H, Misonou Y, Ookawara $\mathrm{T}$, Suzuki K, Honke K, Taniguchi N: Oxidative stress caused by inactivation of glutathione peroxidase and adaptive responses. Biol Chem 2003, 384:567-574.

46. Sharma R, Yang Y, Sharma A, Awasthi S, Awasthi YC: Antioxidant role of glutathione S-transferases: protection against oxidant toxicity and regulation of stress-mediated apoptosis. Antioxid Redox Signal 2004, 6:289-300.

47. Nowling TK, Gilkeson GS: Mechanisms of tissue injury in lupus nephritis. Arthritis Res Ther 2011, 13:250.

48. Hassan SZ, Gheita TA, Kenawy SA, Fahim AT, El-Sorougy IM, Abdou MS: Oxidative stress in systemic lupus erythematosus and rheumatoid arthritis patients: relationship to disease manifestations and activity. Int J Rheum Dis 2011, 14:325-331.

49. Liang J, Zhang H, Hua B, Wang H, Lu L, Shi S, Hou Y, Zeng X, Gilkeson GS, Sun L: Allogenic mesenchymal stem cells transplantation in refractory systemic lupus erythematosus: a pilot clinical study. Ann Rheum Dis 2010, 69:1423-1429.

50. Chang JW, Hung SP, Wu HH, Wu WM, Yang AH, Tsai HL, Yang LY, Lee OK: Therapeutic effects of umbilical cord blood-derived mesenchymal stem cell transplantation in experimental lupus nephritis. Cell Transplant 2011, 20:245-257

doi: $10.1186 /$ scrt408

Cite this article as: Li et al.: Glutathione S-transferase Mu 2-transduced mesenchymal stem cells ameliorated anti-glomerular basement membrane antibody-induced glomerulonephritis by inhibiting oxidation and inflammation. Stem Cell Research \& Therapy 2014 5:19.

\section{Submit your next manuscript to BioMed Central and take full advantage of:}

- Convenient online submission

- Thorough peer review

- No space constraints or color figure charges

- Immediate publication on acceptance

- Inclusion in PubMed, CAS, Scopus and Google Scholar

- Research which is freely available for redistribution 